\title{
Conjunction of Local and Global Processes Towards Qualitative Integrated Urban Development of Danube Region
}

\author{
Miodrag Ralevic, University of Novi Pazar, Novi Pazar, Serbia; Tatjana Mrdjenovic, University of Belgrade, Belgrade, \\ Serbia; Esad Muminović, State University of Novi Pazar, Novi Pazar, Serbia
}

\begin{abstract}
We are witnesses of continuous and turbulent complexity process of urban development at every spatial level. The presence of information and communication technologies in every aspect of our life leads to the fact that there is no more "delay" in between global and local changes. This conjunction changes the paradigm of urban development, which is now in networking, communication and integration. This paper discusses these relations described as hypothesis within Castells' paradigm of network society and project identity that should be developed on local level in order to be a part of - a node of global network, and to survive and develop its potentialities and capacities. This paradigm is discussed in relation to $C$. Alexander's, E. Howard's, and P. Geeds' approach in order to define principles and steps of integration of different spatial levels toward more coherent, harmonized urban development. The research applies theoretical approaches of networking towards integrated development of Danube region.
\end{abstract}

Keywords - Globalization, network society, project identity, sustainable development.

\section{INTRODUCTION}

The process of transforming singular urban system into a complex network system is possible through "process of synthesising" human settlements throughout the evolution of the development of the "formation, duration and alteration" of the form and mode of habitation of urbanized space. Human habitat was initially a self-sufficient "checkpoint", then a settlement "crossroads", the point of intersection of population paths through space. We are now facing new challenge: to multiply settlements" "checkpoints" and to interconnect them as much as they are accessible, i.e. attractive, to each other. This is a crucial thing in double-sided globalization processes that are, according to Castells, both a chance and threat for local communities and their urban representation [1]. According to him local communities and urban societies should develop "project identity" based on past, present and future image in order to be competitive in global network [2], therefore to represent a unique node and develop strong relations within local, regional and global network.

At a crucial moment, urban theory and practice are becoming aware of the importance of networking in urban areas, establishing the following principles:

- urban "settlement" in a space is as significant as it is "networked" with other similar or different settlements;

- networking of regions and settlements is done by establishing relations of different types, categories and intensities, which are in function of linking the specificities of settlements by different categories (similarity, opposite, dependency, etc.);
- the number and type of relations between the elements (settlements), the sets of elements (regions) and the whole, is, in fact, "impenetrable" as a function of change over time;

- networking as a complete system can contain and encompass different problem levels, thematic layers, different "circuits and subassemblies", which allows the formation of a large number of different network structures and systems.

The main reasons for the cultural "networking" of Europe's space derive from civilization postulates and the requirements of this time, such as:

- PLURALISM as a basic cultural value, requires and enables respect for cultural diversity and advocates for urban specificities that are (only) possible to be networked under the laws of mutual "attraction";

- MARKET as a basic field of (free) expression of attractiveness;

- ATTRACTIVENESS of particular regions and settlements whose cohesion forces of "ATTRACT" by natural mechanisms encourage "networking" of regions and settlements and Europe into complex network units;

- INFORMATION TECHNOLOGY, which by its innovations grows into a "REPAIRING APPARATUS" (hardware, software, technology, communication, business, ... planning) through which it is possible for every checkpoint (in this case settlement) to be in relation to all other gatherings (regions) and individual elements (settlements, cities, etc.)

\section{The Theoretical Starting Point of Network Structures}

As it is said before, being out of global network is like living in a local cage without any opportunity to benefit from socio-economic and spatial networks. Castells' network society and project identity seeks for integrated spatial planning in developing elements of the network - nodes, structures, relations, systems. In general, quality of places is related to conception of betterment in different urban paradigms, and today to the presence of conditions for integration of plural values.

Glocal spaces and places both promote and affirm past cultural values with a creation of new ones. Opposite to presented instrumental and collaborative approach, it strives to create sustainable 
spaces and places. Those places are created in multidimensional spaces integrating different identities, values, and interests into coherent whole [3]. In that manner, sustainable urban regeneration can give birth to colourful bond between differences. This bond has a strong power to create a coherent picture of common future ("common sense") and the ways of achieving it. In line with our opinion is Reeves claiming that sustainable development, as youngest paradigm, generates the older ones (both rational and collaborative) in integrative manner [4]. This is a fundamental point of sustainability in creation of "added value" through Habermas' "communicative consensus" [5].

In that sense, integrative urban regeneration, i.e. development realizes betterment in holistic manner both instrumental and collaborative, putting places on global map through creation of glocal identity. We would say that sustainable betterment in urban regeneration leans on glocal identity of places. This kind of identity respects global standards together with affirming or creating local uniqueness. The place, affirmed or created in the process of integrative space has preconditions for socio-economic development in global competition, using sustainability for balancing newly created cultural, social, economic and spatial relationships and networking that should lie on Wolckok's developmental social capital opposing Coleman's closed one [6], [7].

The basic "precondition" of networking is the establishment of a "balance" in the form of a value balance between the development potentials of settlements and the networking regions with the aim of further joint mutually stimulating multi-cultural development of the network as a whole.

The urban network system consists of the following:

- A POINT (in this case) of a settlement, which has the role of a NODE in which relational forces from other points intersect;

- CORRIDOR (in this case) spatial and physical flows in which and through which processes of communication and exchange of different people and goods, activities and values between "knot" settlements take place;

- RELATION as a mechanism by which relationships between elements are defined through the types of possible connections (one-way, multi-directional) of different character (physical functional-value) and different intensity and form (feedback, conjunction, etc.).

The primary goal of an active relationship is in identifying, constructing and forming network structures with a view to looking at future development trajectories there are several approaches in recognizing urban networks.

- $\quad$ FIGURATIVE approach of network structure identifies and constructs through recognition of geometrical forms, primarily in the form of planimetry of the area of settlement network.

- CHRONOLOGICAL approach is based on monitoring the evolution of urban networks in space through time by looking at and discovering the present and future rhythms of connecting settlements and arrays.

- STRUCTURAL value process seeks to recognize the characteristics that reflect the QUALITY of points and relationships in the form and through the consideration of cause and effect effects that result from the different SELECTIONS performed by different actors.

- $\quad$ ANALYTICAL procedure is aimed at discovering quantitative and qualitative parameters, which reflect the specificities and potentials of settlements for their networking.

- $\quad$ ACCESS AND NETWORKING PROCEDURES can be multi-layered.

- OPTIONAL procedure aims to form a "model basis" for the application of certain types of networking in order to review the effects as a whole, and to develop the most favourable network development trajectory in the future.

- VECTOR procedure introduces a parameter of constant "variability" of networked structures with the aim of forming dynamic development "scenarios" of development.

- OPERATIONAL-ALGOMETRIC networking process aims to operationalize the flows of activities that take place in space and time, between settlements and regions in order to create conditions for the management (steering) of future development processes (Fig. 1).

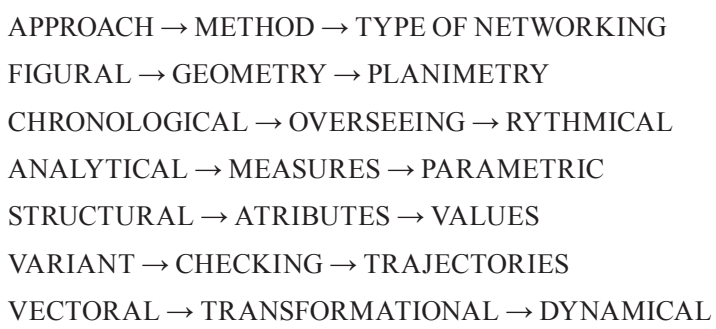

Fig. 1. Formal structure of urban networking [authors of the article].

The process of "understanding" an urban system as a network system is equivalent to a "process of compounding" an urban system that takes place (slow or accelerated) throughout the evolution of the "emergence, duration and development" of human settlements. Until a certain point in its development, human habitat, because of its simple appearance, took the form of a point, later an intersection (nodus), and then, by increasing the elements, it grew into a system, and then expanded and later accelerated to a complex mesh structure (Fig. 2).

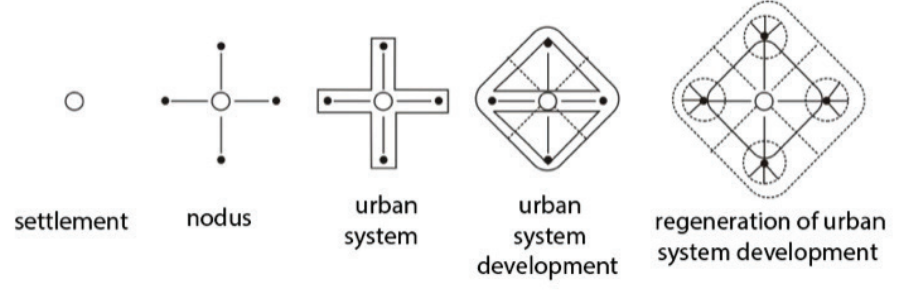

Fig. 2. Illustration of the "complexity" of an urban system and its evolution into a network structure [11] 


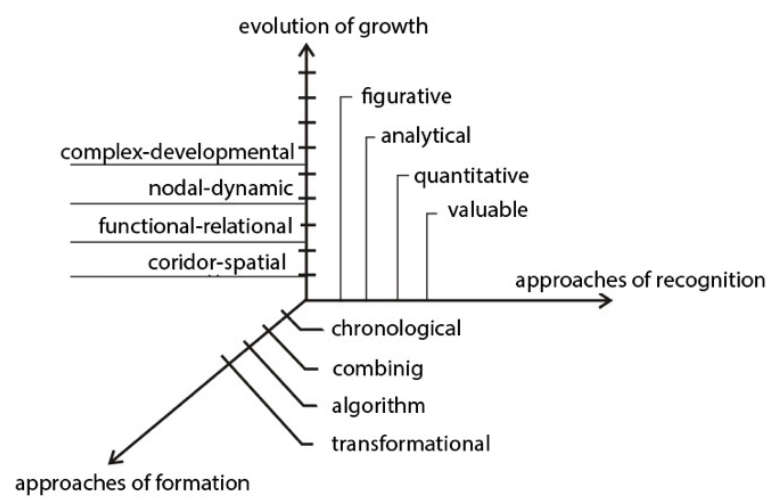

3. Diagram of network structures [11].

The flow of "transformation" of an urban system into a network structure and the flow of (later) insight into its development through the prism of "network development strategies" need to be viewed through three thematic and problem levels:

- the evolution of the "outgrowth" of the urban system into a networked urban structure;

- forms (and modes) of recognizing the emergent forms of networked urban structures;

- $\quad$ procedures (methods and techniques) of forming urban network trajectories (Fig. 3).

SPATIAL-CORRIDOR STRUCTURES grow into networks at the moment when they move from a settlement point to a "path" (corridor) to another point, and the "primary form of a network" emerges the moment it forms (at least one more) points to connect (Fig. 4).
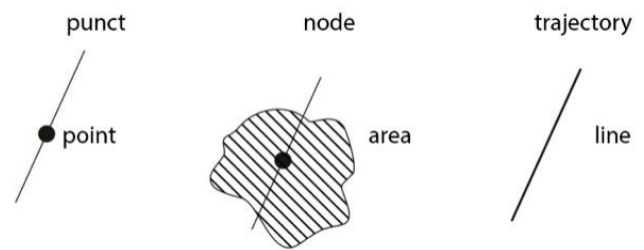

Fig. 4. Illustration of the evolution of the "settlement structure" [11]

The next phase of formation is the connection of corridors-paths of more homogeneous points, then the "quarters" are formed, which leads to an increase in the intensity (and number) of connections, in order to obtain a complex settlement matrix that functions as a spatial-corridor network structure (Fig. 5).

The spatial corridor network structure consists of clearly positioned points (points, objects, surfaces) in space, which are connected by physical corridors profiled for movement (people, goods, energy, etc.) in different forms of routes: roads, streets (jumps, boulevards, etc.), tracks (railway, etc.), ducts (water, electricity-natural or artificial, etc.). The basic feature of such networks is that everything takes place "IN SPACE" and has the qualities of physical determination (Fig. 6).

In this context, different forms of corridor settlement networks emerge: (A) point, (B) radial, (C) circular, (D) linear, (E) compact and (F) dispersive (Fig. 7).

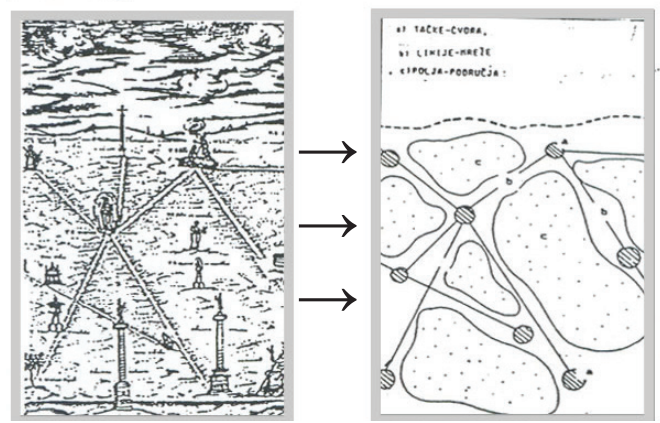

Fig. 5. Illustration of the evolution of the corridor-spatial network [11].

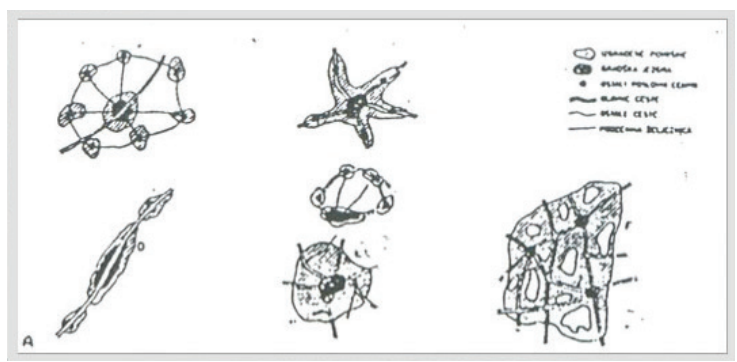

Fig. 6. An example of recognizing the corridor network of medieval Rome [11].

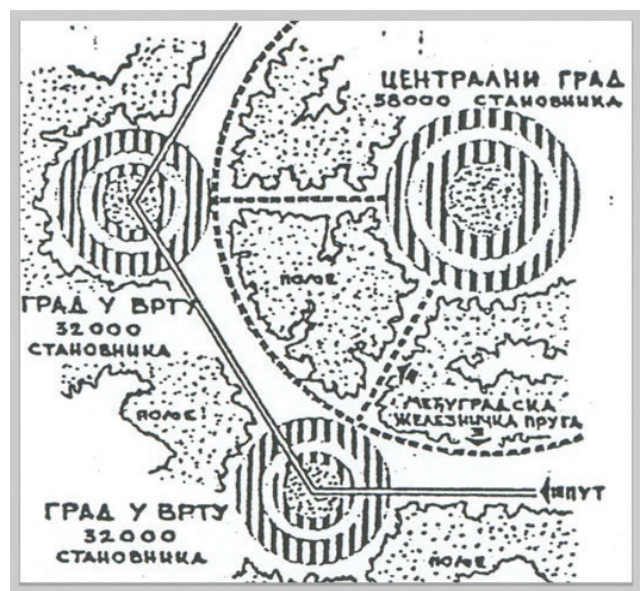

Fig. 7. Examples of different types of corridor settlement structures by E. Howard [8].

FUNCTIONAL-RELATIVE NETWORKS emerge and rely on spatial-corridor network structures, at the moment when they come to know about the relationship between elements (except spatial positions and physical connection) and condition their content component, which becomes as significant as its degree. ATTRACTIONS are compared to other elements. E. Howard (Fig. 8), one of the first urban planners, proposed the development of the region as a system of settlements of different sizes, with one as the central one linking a set of smaller cities in the garden [8].

Therefore, we can identify four basic (phases) forms that have (probably) changed in a certain order, but nowadays all four forms appear simultaneously:

- SPACE-CORRIDOR;

- FUNCTIONAL-RELATIONAL;

- NUTRITION-CHANGEABLE;

- COMPLEX-DEVELOPMENT. 


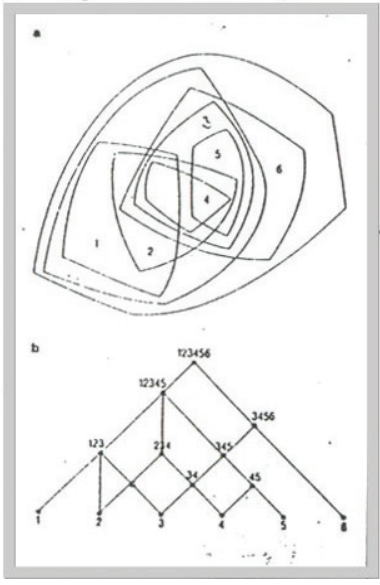

Fig. 8. Spatial-relational network of cities by E. Howard [8].

Cristofer Alexander, by his theory, lays the foundations for recognizing the urban system as a functional-relational network based on the following postulates:

- the urban element in space is not significant in itself, but significant because of the relationships it establishes with other elements;

- the relations between the elements are established (among other things out of space) by several different criteria that carry the character of the function that the element has (similarity, opposite, connectedness, dependence) (Fig. 9) [9].

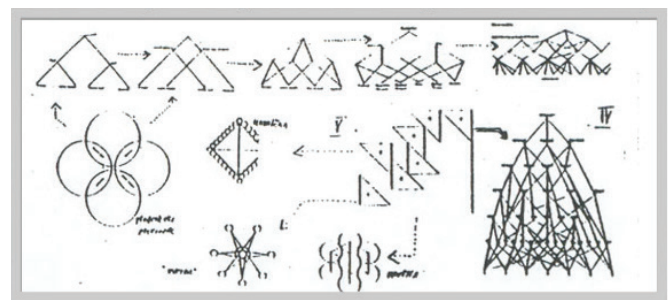

Fig. 9. Structure of old cities whose elements have overlapping relations. By C. Alexander [9].

The number and type of relations between elements, sets of elements, and the whole is virtually "unprecedented", which opens up a large number of possible combinations to form a large number of different relational networks. (Fig. 10).

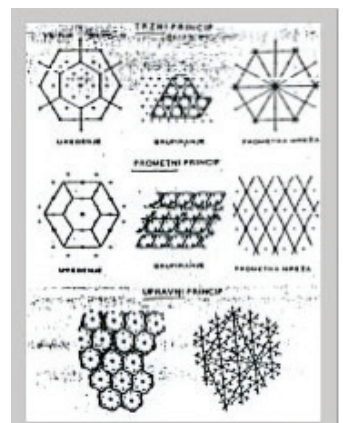

Fig. 10. The evolution of relational networks (by C. Alexander) [9].
"Relational network", as a (graphical) structure, can be recognized, similarly or differently, in different spatial forms (triangular, star, circular, etc.) for different thematic layers of elements or relations.

NODE-CHANGE network structures represent a logical functional-relational upgrade, whereby:

- (most) importance is given to the NOD-point, the point and their attributes;

- a relation becomes a connecting function of a node attribute;

- the attributes of a node become variable, and therefore the relation is changeable, both in character and in the elements it connects (Fig. 11).

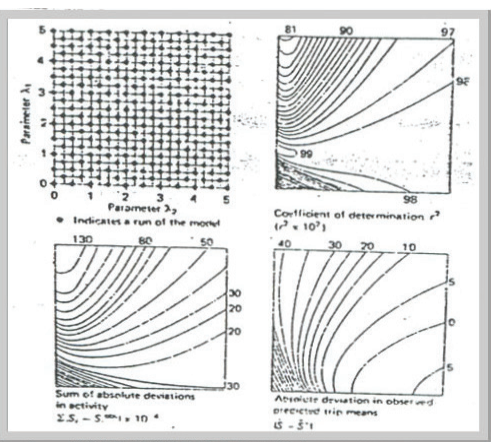

Fig. 11. Illustrations of relativity as a function of attributes of "nodes" [11].

COMPLEX-DEVELOPMENT network structures represent the highest level of complexity, both urban system and network structures. All elements are subject to change and nodes and relationships and corridors. The correlation between the elements is large, so changing any level, on any element (e.g. corridor), brings about equivalent changes over the rest. Thus, changes at some point become primary with respect to other components of the urban system, i.e. network structures. In the function of "constant" variability, network structures are characterized by waves, cannulas, curves, etc. The complexity of the system, expressed by the complexity of the network structures, is resolved by various equivalently complex logical (mathematical) operations (Fig. 12).
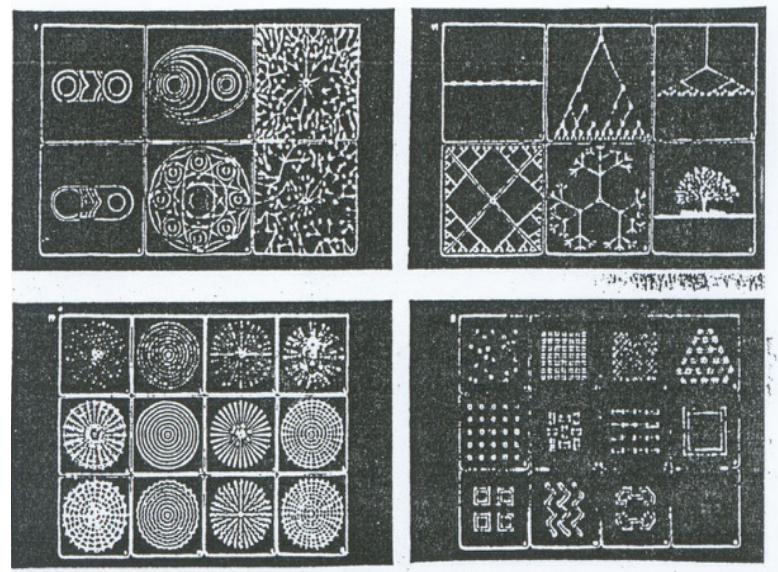

Fig. 12. Illustration of the complex development of the network structure in the form of "waves" [11]. 
II. Model Options for Urban Network Strategies for Danube Region

Essential conception in the strategy making is ' SCIENCE" according to which we can formalize the network strategy into a function of four problem fields:

- the operational field has the function of ACTIVATING development at the right moment, in the right place and in the right way;

- the management field is given the task of "DRIVING" the course of development with an adequate time rhythm, the right route;

- the TACTICS field aims to rapidly align the behaviour of all content present, in space over time and / or in time across space (Fig. 13)

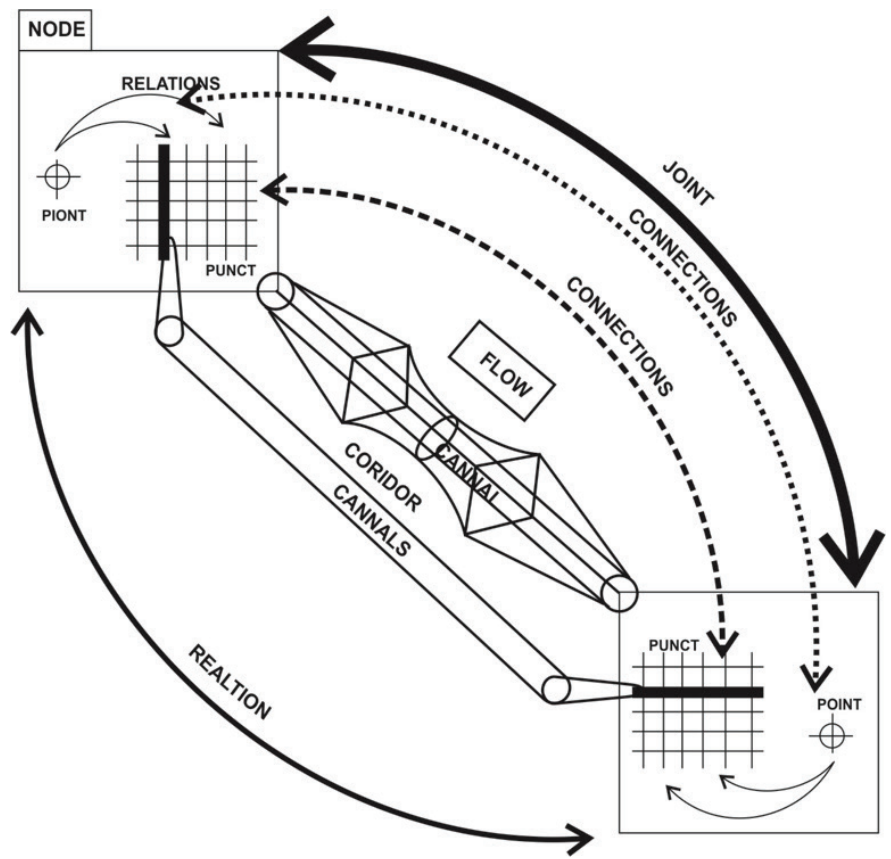

Fig. 13. Modeling matrix of options of network strategy model [11].

There are a number of opportunities to formulate model strategies, starting with the fact that all development can be viewed "only in space", regardless of "duration and content", to the point that everything can be complicated to form a strategy in and through "space and time", with the rapid harmonization of the behaviour of different contents at different spatial points, through different time sequences, with different modes and procedures of realization. The main advantage of network structures is that they provide great opportunities to formulate development strategies by combining different relationships between different numbers, layers and levels of urban components.

The network structure, as a form of (systemic) recognition of the urban assembly, enables simultaneous complete coverage of all elements of the system with parallel (reduction or) isolation of its individual segments or / and elements through various forms of formation of dynamic development trajectories:
- $\quad$ activating the development of elements (together or separately), at different times, in different ways, at different rhythms;

- looking at the development of network structures through special (and / or joint) structuring of behaviour at different (mutually separate) levels; especially the level of development of nodal behaviour, taking into account structured variability of behaviour of relations between components and "special" behaviour of content through "spatio-temporal" corridors;

- composing "development trajectories", both through separate tracing, "behaviour", for each element individually (for each node individually, corridor separately and relations separately), and through "tracing" of combined "behaviour" of different number of components (nodes, each other, nodes and corridors, corridors and relationships, etc.) at different problem levels.

In the context of the above possibilities, we can recognize the following groups of dynamic modeling of network strategies (trajectories) of urban development systems:

- ATRIBUTIVE-VALUE development models;

- DOT-PUNKTONAL trajectories;

- $\quad$ LINE-CORRIDOR development strategies;

- MATRIX-STRUCTURAL DEVELOPMENT NETWORKS;

- RELATIVE-EVOLUTION network strategies;

- COMPLEX-ACTIVATING development strategies.

Taking into account the complexity of the requirements of the initiated process of cultural integration of the European space, the process of networking of settlements and the Danube region, has multiple possibilities, starting from the choice of different methodological starting points, through combining various "networking" techniques, to realizing the combination of different types of network structures in terms of layering and by the complexity of the spatio-temporal span.

In this sense, building on the "original characteristics" of the Danube region, which is formed (traced and grouped) and extends "along and around" the river flow (and layers) of the Danube (Fig. 14), a set of different model bases of networking will be offered "in the order" that stems from primordial traces and time layers that, with their rootedness, have already traced (and in the past started) future processes of cultural integration.

CORRIDOR-MATRIX MODEL OF NETWORKING, for the Danube basin is a starting and basic form, because it is basically a "corridor" of the Danube along and around which different channel networks can be formed:

- "line networks" of settlements, which are formed either parallel to the river flow (in several layers) or along the coastal depth by "linking" a series of settlements with roads to the river;

- "branching" networks that branch along the river into more complex settlement relationships;

- "ray" networks that cluster around a "knot" settlement (or region) through which different streams flow; 
- "star" nets play the role of branching strings of several different ray strings; and

- "matrix-planimetric" networks represent the form of complex (in coverage), rounded (in functioning) and complete networked systems, both in depth and in length of the Danube River.

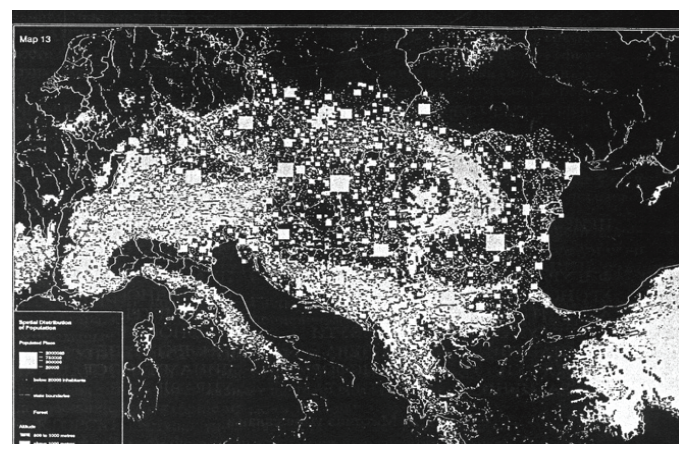

Fig. 14. Diffuse structure of the Danube settlement [11]

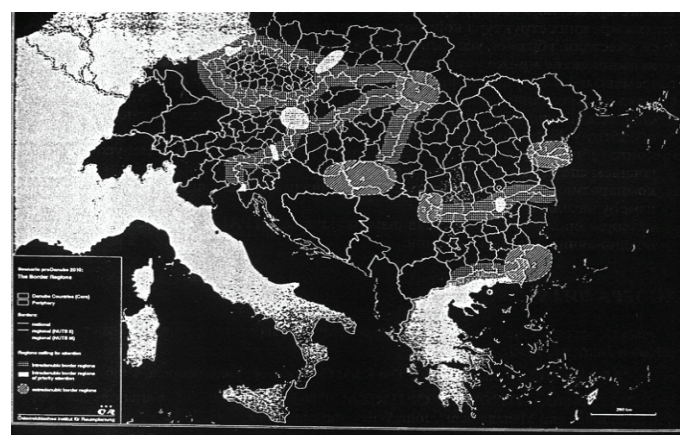

Fig. 15. Cross-border network points [11].

NODE NETWORKS, base their "emergence" on the potentials of a set of nodes that attract each other creating the conditions to outgrow various forms of networking:

- "bulk" networks are formed as a set of spatially separated points that connect to each other according to the "ruling" type of functional connections;

- "clustered" networks, represent a set of nodes connected by a constant cohesive force that attracts them to be simple in a particular activity or content, satisfying the rest of their independence;

- "concentrated" networks are formed by the formation of more dense cohorts, whereby cohesion forces are strengthened whereby settlements grow into a single and complex "node" that acts as a whole;

- "wavy" nets are created by connecting previous node nets, introducing the possibility of changes that take place in the form of oscillations "around, towards, or along" the backbone (in this case) of the Danube river flow.

CUSTOMER-GRAVITY NETWORK for the product of the real needs of the created conditions is for connecting certain settlements and regions with each other. Very often, they are triggered spontaneously by users gravitating toward points and hubs as a function of their forces, which allows the formation of different types of networks:

- "connecting" networks, which are created in succession, tying settlements gradually on the principles of tying, linking, etc.;

- "supply" networks play the role of timely distribution and exchange of goods and services between settlements and regions;

- "distribution networks" have the function of maximizing the potential of the entire network and its individual points;

- communication networks are a product of technological possibilities of connecting settlements, ranging from traffic through media-communication to information-computer forms of networking.

FUNCTIONAL-RELATION NETWORK is based on the importance of the content of a particular POINT (settlement or region) and the type of RELATION with which the greatest effect is achieved by connecting settlements in a comprehensive network.

\section{Conclusions}

The network society that is a product of ICT revolution brings new, previously not known and produced risks for urban settlements, and its regions especially in the context of globalization and new power relations. Giddens says that we live in a runaway world where not developed or developing areas and communities are not having means to benefit from global network [10]. In this sense, there is a tendency for them to separate from the network and stay close in order to survive. On the other hand, Castells claims that being out of the network is a kind of process of vanishing communities, especially related to multicultural societies [2]. Discussion showed that developing different kind of networking and its elements is a way towards integrated, sustainable urban development.

Therefore, the Danube region should develop complex integrated cross-border elements of the network with dynamic nodes (settlements, ports, heritage) [11] that should re-consider their identity towards Castells' project identity using visioning and integrated strategies for creating, establishing and developing existing and new relations-trajectories for socio-economic and cultural exchange and development:

- CORRIDOR-MATRIX MODEL OF NETWORKING;

- PUNCTONAL-NODE NETWORKS;

- $\quad$ CUSTOMER-GRAVITY NETWORK;

- $\quad$ FUNCTIONAL-RELATION NETWORK (Fig. 15).

By establishing permanent relationships, the behaviour of settlements becomes interdependent, and the development of the entire network is conditioned by the "development" of each settlement and its relation with the rest. In this context, the following types of networks can be formed through networking:

- by type of content, they may be monofunctional (linking homogeneous functions), polyfunctional (linking different contents), and multifunctional networks (multilayer relationships between different contents); 
- $\quad$ open, semi-open, and closed network structures can be formed by the integrity of relational networks;

- cyclical networks, which are created by respecting the time course of functioning and the resulting network structures, which may have different rhythms of cycles, such as frequent, accelerated, slow and long-term cycles;

- multicomponent networks contain a greater number of sub-assemblies of networks, introducing at the same time a greater number of criteria, components and parameters, which can be created by establishing different types of functional relations such as:

- existentially-normed networks are the product of established "standards" that provide functional networks;

- compatible networks are created by connecting settlements on the principle of complementarity, strengthening the specificity of each point;

- comparative networks are based on incentive mechanisms competitiveness between settlements; and

- developed networks are created by the mechanisms of strengthening ATTRACTIONS of each individual settlement and networks as a whole.

\section{REFERENCES}

1. Castells, M. The Rise of the Network Society. Oford: Wiley-Blackwell Publishing, 2000. $624 \mathrm{p}$.

2. Castells, M. The power of identity. 2nd Edition. Oxford: Wiley-Blackwell Publishing, 2004. $584 \mathrm{p}$.

3. Mrđenović, T. Urbana regeenracija zaštićenih ambijentalnih celina u kontekstu održivog razvoja - Podgrađe Tvrđave Bač / Urban regeneration of protected ambients in the context of sustainable development - Bac Fortress Suburbium, Univerzitet u Beogradu - Arhitektonski fakultet, Beograd, 2011, e-book, 48 p.

4. Reeves, D. Planning for Diversity: Policy and Planning in a World of Difference. New York: Routledge, 2005. $288 \mathrm{p}$.

https://doi.org/10.4324/9780203506523

5. Habermas, J. The Theory of Communicative Action - Volume One: Reason and the Rationalization of Society. Boston: Beacon Press, 1984. 562 p.

6. Woolcock, M., Narayan, D. Social Capital: Implications for Development Theory, Research and Policy. The World Bank research observer. Vol. 15 , Nr. 2, August 2000, pp. 25-249. http://documents.worldbank.org/curated/ en/961231468336675195/Social-capital-implications-for-development-theory-research-and-policy https://doi.org/10.1093/wbro/15.2.225

7. Coleman, J. S. The Foundations of Social Theory. Cambridge: Belknap Press of Harvard University Press, $1990,993 \mathrm{p}$.

8. Hall, P. Cities of Tomorrow: An Intellectual History of Urban Planning and Design in the Twentieth Century. Oxford: Willey Blackwell Publishing, 2002. $572 \mathrm{p}$

9. Christopher, A., Ishikawa, S., Silverstein, M., Jacobson, M., Fiksdahl-King, I., Angel, S A Pattern Language: Towns, Buildings, Construction. New York: Oxford University Press, 1977. 1171 p.

10. Giddens, E. Odbegli svet: Kako globalizacija preoblikuje naše živote Beograd: Stubovi kulture. 2005. Runnaway World-How Globalisation Shapes our life, Routledge; 1 edition (December 28, 2002), $124 \mathrm{p}$.

11. Ralevic, M. Modeling of urban process, Faculty of Architecture in Belgrade, 2009. $173 \mathrm{p}$.

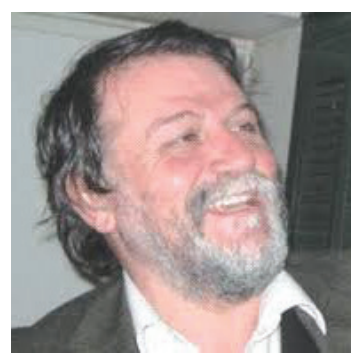

Prof. Miodrag Ralevic is full professor with the University of Novi Pazar as well as with the Faculty of Architecture of the University of Belgrade. During his rich academic and practical work, Prof. Ralevic is an author of more than 100 publications and over 70 urban plans and urban and architectural designs. He works in higher education, on scientific projects. His works have been awardedby national and international juries.

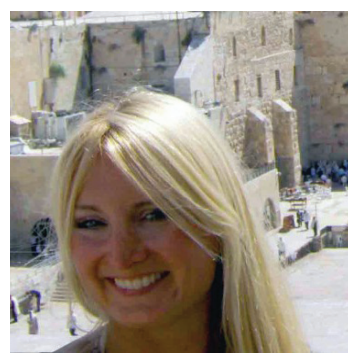

Dr. Tatjana Mrdjenovic is an architect, urban planner and urban designer who is currently an assistant researcher with the Faculty of Architecture, University of Belgrade. Tatjana is an author of three books, presented more than 30 papers at international conferences, and published over 10 papers in domestic and international journals. She has received regional awards for her work. Her field of research is sustainable urban design and urban planning, collaborative approach in planning, new methods and techniques in urban regeneration. She is a member of Serbian Chamber of Commerce, ISOCARP, Serbian Association of Urban Planners and Commissioner at Balkan Architectural Biennale - BAB (Faculty of Architecture, University of Belgrade; mrdenovictatjana@gmail.com)

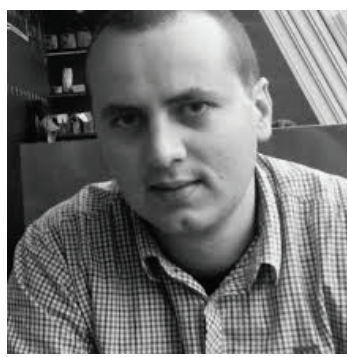

Esad Muminovic currently is a researcher with the Department of Architecture, State University of Novi Pazar. Esad does research in architectural engineering. His most recent publication is "The routes of digitalization: A runaway city?"

\section{Contact Data}

Miodrag Ralevic

E-mail: tenibak.elar@yahoo.com

\section{Tatjana Mrdjenovic}

Faculty of Architecture - University of Belgrade Address: Bulevar kralja Aleksandra 73/2, Serbia

E-mail: mrdenovictatjana@gmail.com,tmrdjenovic@arh.bg.ac.rs ORCID ID: https://orcid.org/0000-0002-6266-385X

\section{Esad Muminovic}

State University of Novi Pazar, Department of Architecture

Address: Vuka Karadžića 9, Novi Pazar, Serbia

E-mail: emuminovic@np.ac.rs 